\title{
Horticultural and other Factors Affecting Aroma Volatile Composition of Small Fruit
}

\author{
Charles F. Forney ${ }^{1}$
}

Additional INDEX WORDs. strawberry, Fragaria, raspberry, Rubus, blueberry, Vaccinium, flavor, ripeness, maturity, storage

Summary. Volatile compounds are responsible for the aroma and contribute to the flavor of fresh strawberries (Fragaria $\times$ anannassa), red raspberries ( $R$ ubus idaeus), and blueberries (Vaccinium sp.). Strawberry aroma is composed predominately of esters, although alcohols, ketones, and aldehydes are also present in smaller quantities. The aroma of raspberries is composed of a mixture of ketones and terpenes. In highbush blueberry (Vaccinium corymbosum), aroma is dominated by aromatic hydrocarbons, esters, terpenes and long chain alcohols, while in lowbush blueberries (Vaccinium angustifolium), aroma is predominated by esters and alcohols. The composition and concentration of these aroma compounds are affected by cultivar, fruit maturity, and storage conditions. Volatile composition varies significantly both quantitatively and qualitatively among different cultivars of small fruit. As fruit ripen, the concentration of aroma volatiles rapidly increases closely following pigment formation. In storage, volatile concentrations continue to increase but composition depends on temperature and atmosphere composition. Many opportunities exist to improve the aroma volatile composition and the resulting flavor of small fruit reaching the consumer.

The value of small fruit, like other fresh horticultural products, depends on the consumer perception of quality. The volatile compounds produced by small fruit create aroma and contribute to flavor, thus strongly affecting quality and value. Depending on the composition and concentration of these volatiles, this effect can be either positive or negative. A desirable, rich, fruity aroma typical of the fruit is often used by the consumer as an indicator of quality, ripeness, and freshness. On the other hand, fermented, moldy, or off-odors, as well as lack of odor, are indicators of spoilage, decay, under ripeness, and general poor quality. Therefore, the volatile composition of the fruit provides the consumer with a good indicator of quality and frequently is used in making a purchasing decision.

Volatile compounds found in fruit are diverse, consisting of hundreds of different chemical compounds (Buttery, 1981; Latrasse, 1991). This diversity is partially responsible for the unique flavors found in different species of small fruit as well as differences among individual cultivars. While volatiles have a major impact on fruit flavor and quality, they are found in very low concentrations, comprising only $0.001 \%$ to $0.01 \%$ of the fruit's fresh weight (Buttery, 1981).

Contribution 2231 of the Atlantic Food and Horticulture Research Centre. I thank Wilhelmina Kalt and Jun Song for their critical reviews of this manuscript.

${ }^{1}$ Postharvest physiologist, Agriculture and Agri-Food Canada, Atlantic Food \& Horticulture Research Centre, 32 Main St., Kentville, N.S., B4N 1J5, Canada; e-mail forneyc@em.agr.ca. 
Volatile compounds are classified based on their presence in the gas state due to their relatively high vapor pressure. Volatile compounds can be detected in the air and their concentration is dependent on the quantity present in the fruit, the temperature, the partitioning coefficient of the compound between liquid and gaseous phases, and diffusion barriers inhibiting its release. A portion of the volatile compounds released into the air by fruit can be detected by human smell thus contributing to the aroma and flavor of the fruit. Certain volatile compounds present indicate the physiological status of the fruit, with specific volatiles indicating stress response, maturity, or decay. This paper will describe the volatiles produced by small fruit, focusing on strawberries, red raspberries, and blueberries. In addition, some factors will be discussed that may affect the composition and concentration of volatiles, which in turn affect quality and value.

\section{Methods of analysis}

The volatile composition of small fruit reported in the literature is dependent on the specific methodology used to collect and analyze the volatile compounds. Because of the diversity of compounds produced by fruit, the methods used for collection, concentration, and analysis can affect the nature of the volatile profile produced and conclusions made. All methods that are currently available have a certain degree of selectivity and therefore some compounds may not be extracted, resolved, or detected depending on the method used (Weurman, 1969; Sugisawa, 1981). In addition, some compounds have poor stability and may degrade under some extraction or analytical procedures (Latrasse, 1991; Pickenhagan et al., 1981). Therefore the limitations of the analytical procedures used to characterize the volatile composition of a fruit must be considered when interpreting experimental results.

The two main methods of extraction and concentration of volatiles involve the use of solvent extraction and head space analysis. When solvent extraction is used, fruit are normally homogenized by cutting, grinding, blending, or pressing prior to extraction (Weurman, 1969). To minimize the formation of artifacts or the loss of some compounds, homogenization is often conducted at cold temperatures and/or under nitrogen atmospheres to minimize these potential changes. Various types of organic solvents are used to extract the volatile compounds (Weurman, 1969). Solvents used include various simple hydrocarbons and alcohols, benzene, dichloromethane, chloroform and diethyl ether. Often combinations of these solvents are used for the extraction solution. Supercritical liquid carbon dioxide can be used in place of many solvents and is effective in extracting lipophilic substances with low volatility (Polesello et al., 1993; Sugisawa, 1981). A single extractant and even combinations are semiselective and do not give a complete extraction of all volatile components (Sugisawa, 1981; Schultz et al., 1967). Therefore the resulting volatile profile is dependent on the solubility of the volatiles in the solvents used. Fruit tissue is normally homogenized in the solvent. To isolate the volatile fraction from the solvent a distillation step is normally required (Weurman, 1969). To obtain a complete profile of volatiles, often two or three distillations of increasing temperature are necessary. However, since small fruit contain few nonvolatile compounds that are soluble in organic solvents, an organic solvent extraction may be acceptable for an extraction of volatiles without a distillation step (Weurman, 1969).

To demonstrate the effects that different extraction and analysis methodologies can have on resulting volatile profiles, the most abundant volatiles reported in ripe 'Senga Sengana' strawberries from four different studies are summarized in Table 1 . The substantial differences in the distribution of volatiles between the four studies is most likely a result of differences in the extraction and analysis methods used. However, as will later be discussed, differences in growing environment, maturity, and postharvest handling could all contribute to these differences. Some of the largest differences were in the furanones, furaneol (2,5-dimethyl-4-hydroxy-3 $2 \mathrm{H})$ furanone) and mesifurane (2,5-dimethyl-4-methoxy-3(2H)furanone).

Table 1. Percent of total strawberry volatiles in 'Senga Sengana' fruit analyzed by different investigators using various solvent extractions and analysis methodologies. Compounds reported are those comprising more than $5 \%$ of the total volatiles reported in any one study.

\begin{tabular}{lcccc}
\hline Compound & Larsen et al., $\mathbf{~ 1 9 9 2 ~}^{\mathbf{z}}$ & ${\text { Hirvi, } \mathbf{1 9 8 3}^{\mathbf{y}}}$ & Schreier, $\mathbf{1 9 8 0}^{\mathbf{x}}$ & Douillard and Guichard, 1990 $^{\mathbf{w}}$ \\
\hline Methyl butanoate & 13.2 & 5.7 & 9.8 & 23.8 \\
Ethyl butanoate & 9.8 & 2.8 & 11 & 11.9 \\
Methyl hexanoate & 1.2 & 0 & 5.2 & 5.1 \\
Ethyl hexanoate & 1 & 11.4 & 11.1 & 2.8 \\
Linalool & 0.9 & 8.5 & 1.6 & 1.1 \\
Hexanol & 0.8 & 10 & 1.8 & 0.1 \\
trans-2-Hexenal & 5.4 & 19.9 & 29.1 & 26.7 \\
2-Pentanone & 6.7 & 0 & 0 & 0 \\
Pent-3-en-2-one & 0 & 0 & 0 & 5.1 \\
Furaneol & 25.2 & 0 & 0 & 2.4 \\
Mesifurane & 24.8 & 34.2 & 2 & 22.3
\end{tabular}

${ }^{\text {z} V o l a t i l e s ~ w e r e ~ e x t r a c t e d ~ f r o m ~ f r e s h ~ f r u i t ~ j u i c e ~ w i t h ~} 2$ diethylether : 1 n-pentane and analyzed on a Carbowax 20M capillary column by gas chromatography-mass spectroscopy. yolatiles were extracted from fresh fruit juice with 2 diethylether : 1 n-pentane and analyzed on a FFAP (acid-modified polyethylene glycol) glass capillary column by gas chromatography-mass spectroscopy-single ion monitoring.

${ }^{x}$ Volatiles were collected onto a cold trap from vacuum distillation at $45^{\circ} \mathrm{C}\left(113^{\circ} \mathrm{F}\right)$ of freshly homogenized fruit. Volatiles were dissolved in pentane-dichloromethane and analyzed on a $5 \%$ FFAP packed column. Values reported are midpoint of ranges.

wolatiles were extracted from freshly homogenized fruit with dichloromethane. Extracts were concentrated and analyzed on an OV351 (acid-modified polyethylene glycol) or a DB 5 ((5\%-phenyl)-methylpolysilxane) capillary column. 
Table 2. Classes of compounds found in strawberries, raspberries, highbush and lowbush blueberries and their range of percent abundance of total volatiles.

\begin{tabular}{lcccc}
\hline Compound & Strawberry $^{\mathbf{z}}$ & Raspberry $^{\mathbf{y}}$ & Highbush blueberry $^{\mathbf{x}}$ & Lowbush blueberry $^{\mathbf{w}}$ \\
\hline Esters & $15-70$ & $5-15$ & $10-60$ & $<0$ \\
Ketones & $1-7$ & $5-15$ & $<1$ & $<10$ \\
Aldehydes & $5-50$ & $10-20$ & $2-10$ & $2-10$ \\
Terpenoids & $1-10$ & $20-50$ & ND & $2-15$ \\
Furanones & $1-30$ & $\mathrm{ND}^{\mathrm{v}}$ & $20-60$ & ND \\
Alcohols & $10-30$ & $2-40$ & ND & $25-60$ \\
Sulfur compounds & $<2$ & $<2$ & ND \\
\hline
\end{tabular}

${ }^{\mathrm{z}}$ Dirinck et al., 1981; Douillard and Guichard, 1990; Hirvi and Honkanen, 1982; and Schreier, 1980.

yGuichard, 1982; Honkanen et al., 1980; Robertson et al., 1995; Schamaila et al., 1993; and Vereshchagin and Bezzubov, 1981.

${ }^{x}$ Forney et al. (unpublished data); Hirvi and Honkanen, 1983; and Parliment and Kolor, 1975.

${ }^{\text {w}}$ Forney et al. (unpublished data) and Lugemwa et al., 1989.

${ }^{\mathrm{v}} \mathrm{ND}=$ not detected

Larsen and Poll (1992) reported that these two compounds comprised $50 \%$ of the total volatiles while Schreier (1980) found they only comprised $2 \%$. The furanones are known to be degraded by heat, low $\mathrm{pH}$, and contact with glass capillary gas chromatograph (GC) columns, and therefore differences in methodologies could contribute to differences in furanone recovery (Pickenhagen et al., 1981; Shu et al., 1985).

In head space analysis, volatiles in the air around the whole or homogenized fruit are sampled. Fruit are placed in an inert jar or container that is sealed (static) or continuously purged (dynamic) with air or an inert gas. Purging the head space over homogenized fruit with nitrogen is often used to prevent oxidation of some oxygensensitive volatile compounds. However, since whole fresh fruit are living, purging their head space with nitrogen may induce fermentation and alter their normal volatile composition. Samples of the head space can be taken with a syringe and directly analyzed (Wampler, 1997). However, due to the low concentration of most volatiles and the limited volume that can be analyzed, this approach is only useful for the most volatile and abundant compounds. More commonly, volatiles in the head space are concentrated by trapping them onto cold or chemical adsorbent traps, consisting of tubes packed with glass beads and cooled with liquid nitrogen (cold) or a chemical adsorbent. Chemical adsorbents that are commonly used singly or in combination include activated charcoal, Porapaks, Tenax, silica gel, Carbotrap, Carbopack, and Carboseives (Sugisawa, 1981; Wampler, 1997). Each adsorbent dif- fers in volatile selectivities, water affinity, and thermal stability. Once trapped, volatiles can be thermally desorbed or eluted with a solvent from the trap. Again the choice of method used will influence the volatile profile obtained from the analysis.

A relatively new method for the collection and concentration of volatiles is solid phase micro extraction (SPME) (Ibáñez et al., 1998; Steffen and Pawliszyn, 1996; Song et al., 1998). This method involves the adsorption of volatiles onto coated fibers, which are then thermally desorbed in a GC injection port for analysis. Some selectivity is observed between the different available fibers, but the method can provide quantitative data of the composition of specific volatiles.

Gas chromatography is the most common method of analysis for most volatiles (Teranishi, 1981). Gas chromatography with high resolution capillary columns is very effective in resolving the large and complex mixtures of volatile compounds evolved from fruit. By altering the column chemistry separations can be optimized for compounds of interest. Gas chromatography offers a number of detection options including flame ionization, mass spectroscopy, Fourier transformed infrared (FTIR) spectroscopy, flame photometric, and olfactory detection (Teranishi, 1981). Because of the diversity and complexity of the volatile compounds, often mass spectroscopy and to a lesser extent FTIR spectroscopy are used to aid in identification (Flath, 1981; Gomes da Silva and Chaves das Neves, 1999). Olfactory detection, where column effluent is evaluated by persons trained in odor evaluation, is used to identify compounds that contribute to the aroma and flavor of small fruit (Rizzolo, 1998; Ulrich et al., 1997). In addition to GC, high performance liquid chromatography (HPLC) may be used for some higher molecular weight and/or thermolabile compounds that are not amenable to separation by GC. The furanones are one group of compounds found in small fruit that have been analyzed using HPLC (Sanz et al., 1995 ).

A new technology for the analysis of head space volatiles is referred to as the electronic nose. These instruments use head space analysis, a series of semiconductor sensors, and pattern recognition software to characterize volatile composition (Dickinson et al., 1996; Kinoshita and Nagata, 1998; Newman, 1991). The electronic nose does not have the specificity of chromatographic techniques for specific compound identification, but it can be useful to screen for changes in volatile profiles and does have application for quality control. Electronic nose technology has been used to identify and sort unripe and damaged blueberries from good fruit (Simon et al., 1996).

\section{Volatile composition}

Most of the volatiles responsible for the aroma of small fruit are classified as esters, ketones, aldehydes, terpenoids, furanones, alcohols, or sulfur compounds. In general, strawberries are dominated by esters, raspberries have higher quantities of terpenoids, and blueberries are dominated by esters and alcohols (Table 2). However, the volatile profiles of these fruit are complex and vary significantly depending on cultivar, ripeness, pre- and postharvest environmental conditions, and analysis methods used (Forney et al., 2000). 
Of all the small fruit, the most work on characterizing volatile composition has been conducted with strawberry fruit. Over 360 different volatile compounds have been identified in strawberry fruit (Latrasse, 1991). These include over 130 different esters, which provide fruity and floral characteristics to the fruit aroma (Gomes da Silva and Chaves das Neves, 1999; Latrasse, 1991). Esters encompass between $25 \%$ to $90 \%$ of the total volatiles in ripe strawberry fruit (Forney et al., 2000). Aldehydes and furanones also contribute to the strawberry aroma and may comprise a significant portion of the volatiles (Schreier, 1980; Larsen and Poll, 1992). Terpenoids and sulfur compounds normally make up a small portion of the strawberry volatiles but they may make a significant impact on the character of the fruit aroma (Dirinck et al., 1981; Schreier, 1980). On the other hand, up to $35 \%$ of the total volatiles may be alcohols, but they contribute little to the fruit aroma. The most abundant volatile compounds reported to be in fresh strawberries include methyl butanoate, ethyl butanoate, ethyl hexanoate, trans 2-hexenal, mesifurane, hexanal, methyl hexanoate, and fureneol (Douillard and Guichard, 1990; Gomes da Silva and Chaves das Neves, 1997; Larsen et al., 1992; Pérez et al., 1997a; Schreier, 1980)

More than 200 volatile compounds have been identified in raspberry fruit (Latrasse, 1991), although in most studies for a given cultivar $<100$ were reported (Buttery, 1981; Guichard, 1982; Robertson et al., 1995). Volatile profiles were dominated by terpenoids, with similar numbers of ketones, aldehydes, esters, and alcohols normally present (Table 2 ). Honkanen et al. (1980) extracted over 60 volatiles from wild Finnish raspberries. The composition was similar to that of cultivated raspberries containing about $30 \%$ terpenoids, $27 \%$ ketones and aldehydes, 23\% alcohols, $13 \%$ esters, and $5 \%$ furanones. The most abundant compounds reported in raspberries include benzaldehyde, $\alpha$-pinene, $\alpha$ - and $\beta$-ionone, $\beta$ caryophellene, geraniol, $\beta$-myrcene, $\gamma$ terpinene, trans $\beta$-ocimene, ethyl acetate, ethyl heptanoate, raspberry ketone, and 2-methyl butanol (de Ancos et al., 2000; Larsen and Poll, 1990; Robertson et al., 1995; Shamaila et al., 1993).
In blueberries, fewer volatile compounds have been isolated and identified than in strawberries and raspberries. In addition, the quantity of volatiles in blueberries is much less, reflecting the fact that they are less aromatic than other small fruit. Reported concentrations of volatiles range from 0.5 to $0.75 \mathrm{mg} \cdot \mathrm{kg}^{-1}$ (ppm) for fresh highbush blueberries (Di Cesare et al., 1999; Hirvi and Honkanen, 1983) compared with 2 to $6 \mathrm{mg} \cdot \mathrm{kg}^{-1}$ for strawberries (Hirvi, 1983) and as much as $62 \mathrm{mg} \cdot \mathrm{kg}^{-1}$ for wild raspberry (Honkanen et al., 1980). In highbush blueberries, alcohols and esters each comprise about a third of the volatile compounds identified, while terpenoids comprised an additional $20 \%$ to $30 \%$, although this distribution varies among cultivars (Table 2). Some of the most abundant compounds in these fruit included ethanol, 1-ethyl-1hexanol, phenol, methyl acetate, 2methylpropyl 3-methylbutanoate, benzyl alcohol, 4-vinylphenol, farnesyl acetate, and linalool (Di Cesare et al., 1999; Forney et al., unpublished data; Hirvi and Honkanen, 1983).

In wild lowbush blueberries, head space volatiles collected from whole fruit varied significantly among clones. Esters comprised between 10 to $50 \%$ of the compounds identified, alcohols $25 \%$ to $40 \%$, and terpenoids 2 to $15 \%$ (Table 2). The most abundant compounds included benzaldehyde, ethanol, 2- and 3-methyl-1-butanol, 1ethyl-1-hexanol, phenol, methyl, ethyl, and isopropyl acetate, 2-methylpropyl 3-methylbutanoate, and methyl 3methylbutanoate (Forney et al., unpublished data; Lugemwa et al., 1989). Baloga et al. (1995) isolated 36 volatile compounds from the headspace of juice extracted from seven other species of diploid wild blueberries. These compounds included 13 esters, 7 hydrocarbons, 6 aldehydes, 5 alcohols, and 3 ketones.

Homogenization of fresh blueberries results in a large increase in concentrations of $\mathrm{C}_{6}$ alcohols and aldehydes. When volatiles were compared from the head space of whole and homogenized highbush blueberry fruit from three different cultivars, hexanols, hexenols, hexanals and hexenals comprised $11 \%$ to $16 \%$ of the total volatiles in homogenized compared to $0 \%$ to $2 \%$ in whole fruit, while in three clones of lowbush blueberries, these compounds comprised $11 \%$ to
$44 \%$ in homogenized compared to $0 \%$ to $3 \%$ in whole fruit (Forney et al., unpublished data). In a similar study, over $91 \%$ of the total volatiles collected from homogenized highbush blueberries were recovered in these $\mathrm{C}_{6} \mathrm{com}$ pounds, with $71 \%$ as trans-2-hexenal and $12 \%$ as trans-2-hexenol (Parliment and Kolor, 1975).

\section{Aroma-active volatiles}

The importance of different volatile compounds is dependent on their contribution to the fruit's aroma. The human nose has a wide range of sensitivities to different volatile compounds. The odor threshold, which is the lowest concentration of a volatile that can be smelled, may range by as much as $10^{6}$ - to $10^{8}$-fold among volatiles found in fruit (Table 3 ). Because of this wide range of odor thresholds, the most abundant volatiles are not necessarily the most important contributors to the fruit aroma. As a result, much attention has been given to the identification of volatile compounds responsible for the desirable aroma and flavor of fruit. Identification of odor active volatiles has been done by using aroma values, which are calculated by dividing the concentration of the compound in the fruit by its odor threshold (Larsen and Poll, 1992). Odor active compounds are also identified and ranked using gas chromatography olfactometry (GCO), where volatile compounds separated through gas chromatography are identified and ranked by the nature and intensity of their smell using trained evaluators (Roberts and Acree, 1996).

Summarizing a number of strawberry volatile studies that used both aroma values and GCO, the volatiles that consistently ranked as important

\begin{tabular}{|c|c|}
\hline 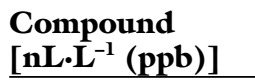 & $\begin{array}{l}\text { Olfactory } \\
\text { threshold } \\
\end{array}$ \\
\hline Ethanol & $10,000-100,000^{z}$ \\
\hline Ethyl acetate & $100-1,000^{y}$ \\
\hline Methyl butanoate & $1.0-10^{y}$ \\
\hline Linalool & $0.1-1.0^{y}$ \\
\hline Ethyl hexanoate & $0.01-0.1^{y}$ \\
\hline Ethyl butanoate & $0.001-0.01^{\mathrm{y}}$ \\
\hline
\end{tabular}

${ }^{\mathrm{z}}$ Devos et al., 1990.

yLarsen and Poll, 1992. 
aroma compounds included ethyl butanoate, ethyl hexanoate, methyl butanoate, ethyl 3-methylbutanoate, fureneol, and linalool (Forney et al., 2000). Additional compounds that have been reported to contribute to aroma include 2-heptanone, mesifurane, cis-3-hexenal, ethyl 2methylpropanoate , 2,3-butanedione, 3-methylbutyl acetate, methyl hexanoate and ethyl 2-methylbutanoate. Pérez et al. (1997a) divided strawberry volatiles into 3 groups based on the nature of their aroma. These were fruity odor notes, which included the esters, methyl butanoate, ethyl butanoate, butyl acetate, methyl hexanoate, and ethyl hexanoate; green odor notes, which included hexanal, 2-hexenal, hexyl acetate, and hexanol; and sweet odor notes which included furaneol.

Raspberries have been reported to contain an aroma impact compound, which is a single compound that has an odor characteristic of raspberry. This compound has been identified as $1-(p-$ hydroxyphenyl)-3-butanone and is referred to as raspberry ketone. Borejsza-Wysocki et al. (1992) reported that raspberry ketone content correlated positively with organoleptic evaluations of flavor intensity. This compound has not been reported to be present in some studies of raspberry aroma. However, because of raspberry ketone's high boiling point, it may not have been detected under some of the analysis procedures used.

When aroma values were determined for volatiles from fruit of 10 different raspberry cultivars, $\beta$-ionone was ranked as the most important aroma compound, followed by raspberry ketone, $\alpha$-ionone, geraniol, and linalool (Larsen and Poll, 1990). Using olfactory detection, Roberts and Acree (1996) ranked the top odor active compounds in fresh 'Heritage' raspberries under both a head space analysis simulating chewing in the mouth (retronasal aroma simulator) or a solvent extraction. From the head space analysis, the top aroma impact compounds were $\beta$-damascenone, diacetyl, sotolon, 1-hexen-3-one, 1nonen-3-one, 1 -octen-3-one, and cis3 -hexenal. From the solvent extraction, the most odor active compounds were $\beta$-damascenone, ethyl 2 methylbutanoate, ethyl butanoate, raspberry ketone, vanillin, cis-3hexenal, and $\beta$-ionone. The solvent extraction favors the less volatile compounds with higher boiling points whereas the head space method favors the more volatile compounds with lower boiling points. The use of head space analysis with solvent extraction may be complementary to obtain a full profile of the compounds responsible for fruit flavor.

In blueberries, volatile compounds contributing to the aroma of fresh whole fruit were identified by using GCO (Forney et al., unpublished data). In highbush blueberries, important aroma compounds included butyrolactone, terpineol, 6-ethyl 2,6decadiene-4,5-diol, linalool, benzaldehyde, and 2-ethyl-2-hexenal. Hirvi and Honkanen (1983) reported that the volatile compounds hydroxycitromellol, farnesyl acetate, farnesol and myristicine, found in juice of frozen 'Rancocas' highbush blueberries, may contribute to the blueberry aroma. These compounds were determined to have fruity or blueberry-like odors by panelists evaluating pure compounds. However, most of these identified compounds had odor thresholds greater than the concentration present in the fruit, bringing into question their contribution to blueberry aroma. In another study, fractions of effluent from a gas chromatographic separation of highbush blueberry volatiles were isolated and evaluated for flavor contribution (Parliment and Scarpellino, 1977). From this evaluation, it was determined that a combination of linalool and cis-3-hexenol produced a blueberry-like flavor. Similarly, Horvat and Senter (1985) reported that a mixture of cis-3-hexenol, trans-2hexenol, trans-2-hexenal, linalool, and geraniol gave an aroma similar to the aroma isolated from blueberries.

In lowbush blueberries, the major odor active volatiles were different than in highbush blueberries and were dominated by esters (Forney et al., unpublished data). Important odor active compounds identified included methyl 3-methylbutanoate, ethyl 3methylbutanoate, ethyl 2-methylbutanoate, methyl 2-methylbutanote, linalool, and methyl butanoate. Other wild species of diploid blueberries were reported to contain ethyl-2-methylbutanoate, trans-2-hexenal, and linalool in their juice and were reported to be the major contributors to their blueberry aroma (Baloga et al., 1995).

\section{Factors influencing volatile composition}

Due to the complex nature of the volatile profiles, volatile composition is continuously changing in fresh fruit. Many factors affect volatile composition including the genetic make up of the fruit, its maturity, environmental conditions during production, post harvest handling, and storage. To date we have a limited understanding of how these factors interact to determine the actual volatile composition and resulting flavor of the fruit. The remainder of this report will look at some of these factors and the current understanding of how they affect fruit aroma.

Cultivar. Different cultivars of small fruit varied significantly in their volatile content both quantitatively and qualitatively. These differences can help to explain flavor differences that were commonly noted among cultivars. Total volatile content of ripe strawberry fruit from different cultivars varied up to 35-fold (Forney et al., 2000). Within cultivars, the abundance of esters and other compounds also varied significantly. Methyl esters were dominant in many cultivars including 'Hokowase', 'Kent', 'Senga Gigana', and 'Annapolis', comprising more than $70 \%$ of the total volatiles (Dirinck et al., 1981; Forney et al., 2000; Miszczak et al., 1995; Ueda and Bai, 1993). In other cultivars, including 'Configra' and 'Chandler', ethyl esters comprised $80 \%$ and $60 \%$ of the total volatiles, respectively (Dirincket al., 1981; Pérez et al., 1992). Other volatiles that contribute to fruit aroma also varied among cultivars. Volatiles that were prominent in specific cultivars include ethyl 3-methylbutanoate and 3-methyl acetate in 'Kent' and 'Micmac', hexyl acetate in 'Honeoye' (Forney et al., 2000), furaneol in 'Senga Sengana', 'Parker', and 'Benton' (Larsen and Poll, 1992; Sanz et al., 1995), and linalool in 'Senga Sengana' and 'Annelie' (Hirvi and Honkanen, 1982; Larsen and Poll, 1992).

Differences in volatile content were also apparent among raspberry cultivars. When the cultivars 'Newburgh' and 'Novost' Kuz'mina' were compared, the later had over 3fold more volatiles (Vereshchagin and Bezzubov, 1981). 'Novost' Kuz'mina' had greater quantities of alcohols and 
Table 4. Relative amounts of terpenoid compounds isolated from the headspace of three raspberry cultivars. Data from Shamaila et al., 1993.

\begin{tabular}{lccc}
\hline & \multicolumn{3}{c}{ Normalized peak area counts } \\
\cline { 2 - 4 } Compound & \multicolumn{3}{c}{ Cultivar } \\
\cline { 2 - 4 }$\alpha$-Pinene & Chilliwack & Meeker & Tulameen \\
$\beta$-Myrcene & 40.1 & 9.8 & 3.1 \\
$\gamma$-Terpinene & 62.2 & 74.1 & 43 \\
$p$-Cymene & 46.3 & 97 & 54 \\
Sabinene & 8.7 & 19 & 9.9 \\
$\beta$-Ionone & 4.2 & 7.5 & 3.1 \\
Caryophylene & 29.3 & 18.7 & 21.3 \\
& 22.2 & 7.2 & 12.9
\end{tabular}

${ }^{\mathrm{z}}$ Ratio of peak area counts from a gas chromatography-mass spectroscopy analysis with those of a 2-nonanone internal standard.

carbonyl compounds, whereas 'Newburgh' had more terpenoid compounds. The distribution of terpenoids in three raspberry cultivars is listed in Table 4. The compounds $\alpha$-pinene, caryophyllene, and $\beta$-ionone are high in 'Chilliwack', while $\gamma$-terpinene, $p$ cymene, sabinene, and $\beta$-myrcene are high in 'Meeker'. The cultivar 'Tulameen' was low or intermediate in its content of these terpenoids. In a similar comparison of Spanish-grown raspberry cultivars, 'Heritage' had higher amounts of volatiles than 'Autumn Bliss', 'Zena', or 'Rubi' (de Ancos et al., 2000). Raspberry cultivars also vary significantly in their content of raspberry ketone (Borejsza-Wysocki et al., 1992). Cultivars such as 'Canby' and 'Royalty' contained $<30 \mu \mathrm{g} \cdot \mathrm{kg}^{-1}$ (ppb) while 'Willamette' contained over $170 \mu \mathrm{g} \cdot \mathrm{kg}^{-1}$.

Maturity. The production of aroma volatiles is integrated with the ripening process with volatile profiles changing dramatically during ripening. During the $2 \mathrm{~d}$ required for strawberry fruit to turn fully red, esters responsible for strawberry aroma increased about 20 -fold (Ito et al., 1990). Similarly, in 'Kent' fruit, head space volatile concentration was 100 -fold greater in red-ripe fruit compared to pink fruit that were just starting to ripen (Miszczak et al., 1995). After fruit have turned fully red the volatile content continues to increase, with the ester concentration doubling $\mathrm{l} \mathrm{d}$ after the fruit were fully red (Fig. 1). Throughout ripening the rates of change in concentration of individual volatiles vary, resulting in a continuous change in flavor.

Similar to the esters, the furanones increase during ripening. In four strawberry cultivars, concentrations of furaneol, mesifurane, and furaneol glucoside increased during ripening reaching a maximum when fruit were overripe (Pérez et al., 1996). Dark-red, overripe fruit contained 2 - to 3 -fold more furaneol than red ripe fruit. Differences tended to be greater for mesifurane and furaneol glucoside. While many of the flavor compounds increase, Pérez et al. (1992) found the $\mathrm{C}_{6}$ alcohols decreased, which may explain the loss of the green, immature odor as strawberries ripen. ppm; adapted from Forney et al., 2000.
In raspberry fruit, aroma volatiles increase during color formation and ripening. During the ripening of 'Glen Prosen' raspberries, several monoterpenes including camphene, $\beta$-myrcene, and limonene rise steadily, as well as the compounds $\alpha$-phellandrene, $\alpha$ pinene, $\alpha$-ionone, $\beta$-ionone, methyl acetate, ethyl acetate, 2 -methyl-1-butanol, and cis-3-hexenol (Robertson et al., 1995). In addition, the concentration of volatiles associated with green leaves including cis- $\beta$-ocimene and trans- $\beta$-ocimene declined. Several odor active terpenoids also increased during the ripening of both 'Rose de Côte d'Or' and 'Lloyd George' raspberries (Fig. 2.). After fruit become fully-ripe, changes in these compounds slowed and overripe fruit had a similar concentration to ripe fruit in most cases.

During the ripening of rabbiteye blueberries (Vaccinium ashei), the concentrations of low molecular weight volatiles tended to decrease while higher molecular weight compounds increased (Horvat and Senter, 1985). The compounds trans-2-hexenal, trans-2-hexenol, cis-3-hexenol, $\alpha$-terpineol, and $\beta$-caryophyllene all de-

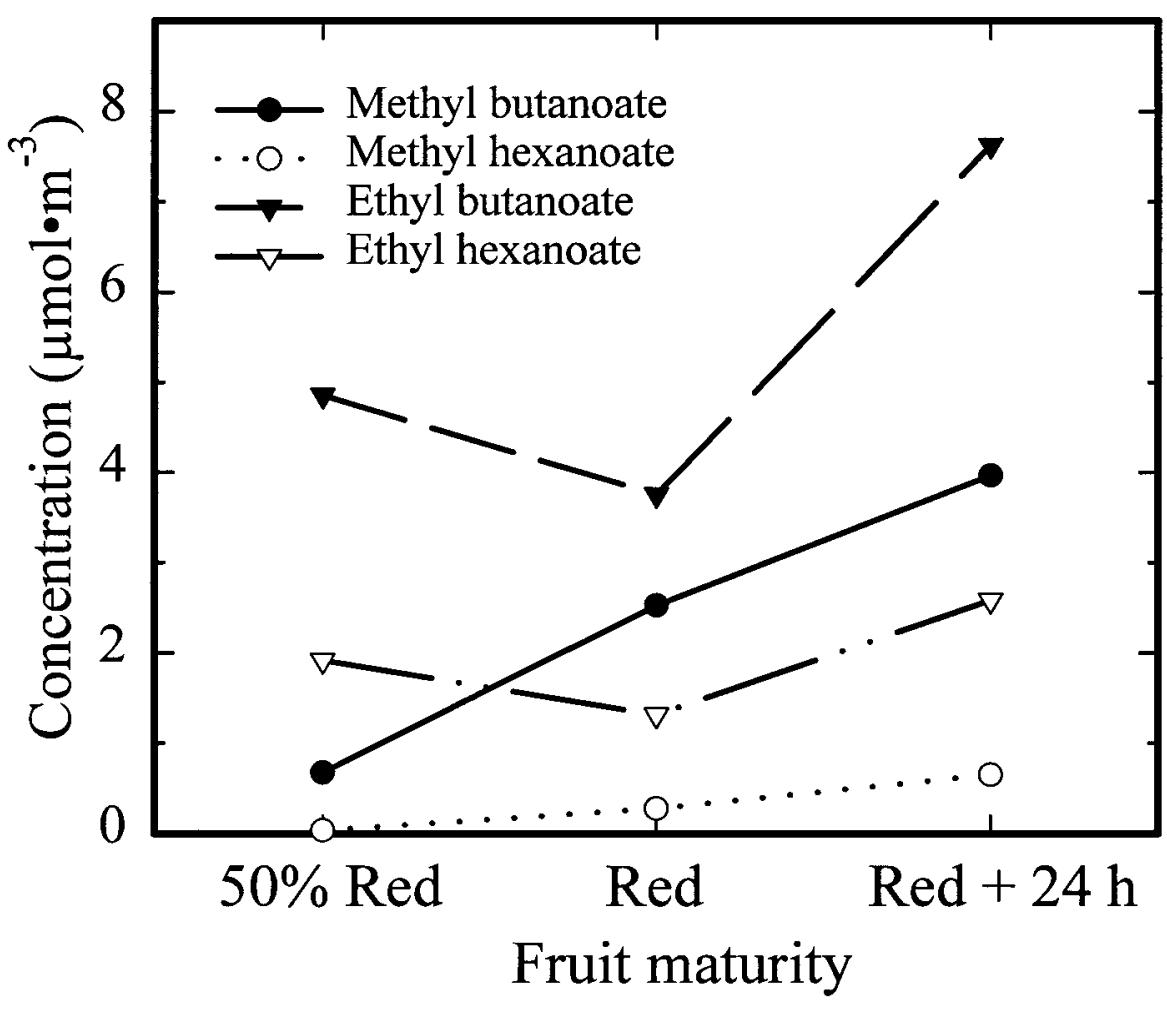

Fig. 1. Changes in the head space concentration of aroma esters in strawberry fruit harvested at three different maturities. Fruit were harvested when $\mathbf{5 0 \%}$ red $(50 \%$ Red), on the day the fruit turned fully red (Red), or on the following day $(\operatorname{Red}+24 \mathrm{~h})$. Values are the average of five cultivars; $1 \mu \mathrm{mol} \cdot \mathrm{m}^{-3}=23.8$ 


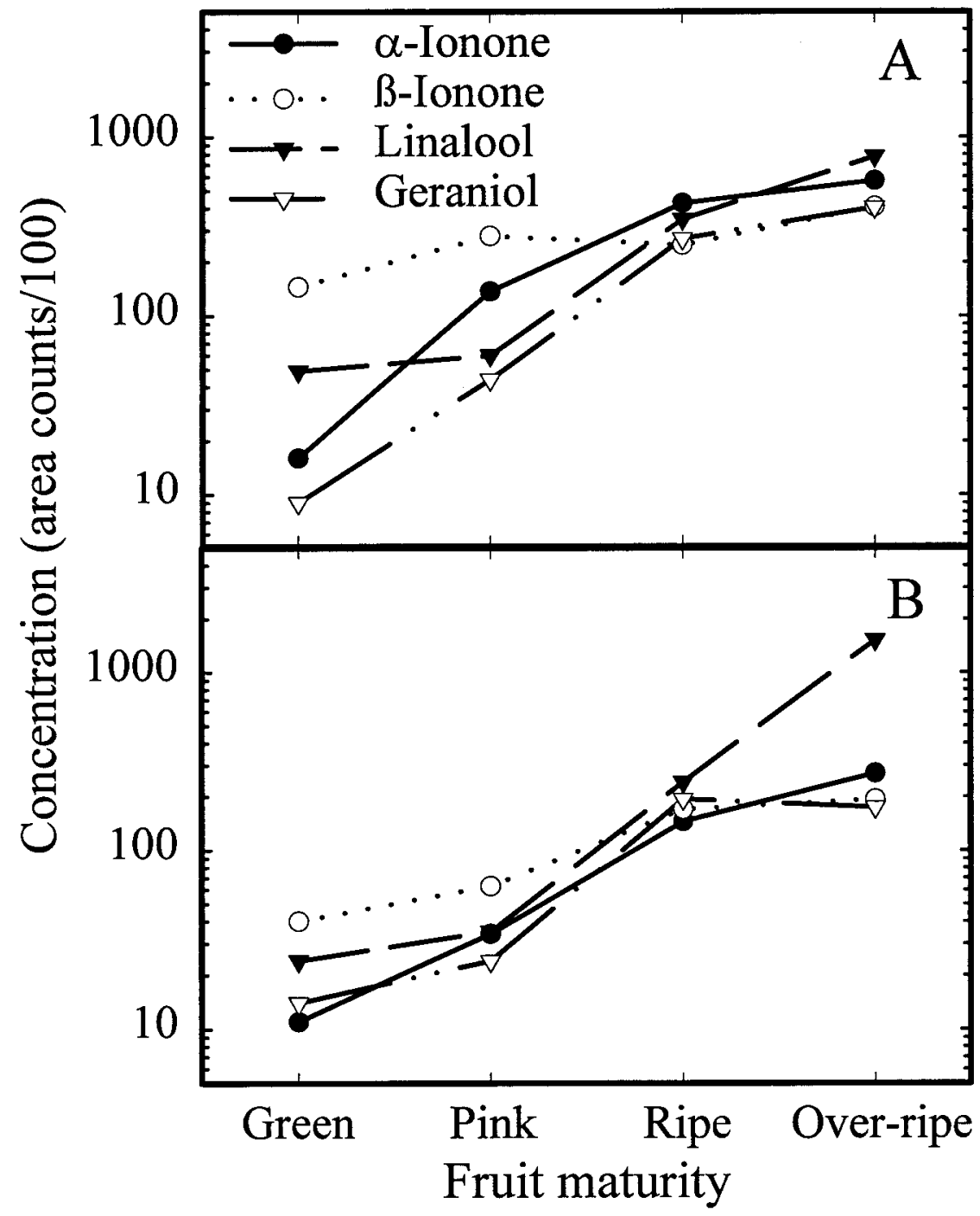

Fig. 2. Changes in the concentration of aroma active volatiles in 'Rose de Côte d'Or' (A) and 'Lloyd George' (B) raspberries during ripening; adapted from Guichard, 1984.

creased in concentration as fruit progressed from green to midripe to fully ripe. However, linalool and geraniol concentrations were equal or greater in midripe and ripe than in green fruit (Horvat et al., 1996; Horvat and Senter, 1985).

Postharvest changes. During storage and marketing, good flavor needs to be maintained to supply the consumer with high quality fruit. Limited research has been conducted on changes in small fruit volatiles during postharvest handling. However, it appears that changes in volatile composition continue after harvest through new synthesis, as well as volatile loss, resulting in a continual change in the overall volatile profile. These changes cause both positive and negative flavor changes in the fruit during marketing.

In strawberries, volatile concentrations continue to increase after har- vest. Total head space volatiles of redripe harvested fruit increased about 7 fold after $4 \mathrm{~d}$ at $15^{\circ} \mathrm{C}\left(59^{\circ} \mathrm{F}\right)$ (Fig. 3$)$. Volatiles in pink-underripe harvested fruit also increased but not nearly as much as in ripe fruit. White fruit never produced significant quantities of volatiles. This indicates that strawberry fruit harvested underripe never reach their full flavor potential and harvest maturity must be carefully managed in order to supply a high quality fruit in the market. When individual volatiles are monitored, postharvest increases occur for most of the major aroma volatiles including esters (Miszczak et al., 1995; Forney et al., 2000) and furanones (Pérez et al., 1996).

Postharvest temperature appears to affect volatile composition. In strawberries stored at $1{ }^{\circ} \mathrm{C}\left(34^{\circ} \mathrm{F}\right)$, ethyl esters increased while methyl esters did not (Forney et al., 1998). When fruit were warmed to $15^{\circ} \mathrm{C}$, methyl esters increased, with little change in ethyl esters. A similar increase in methyl esters was observed in fruit in the field where temperatures ranged from 12 to $30^{\circ} \mathrm{C}\left(54\right.$ to $86^{\circ} \mathrm{F}$ ) (Forney et al., 2000). This indicates that the postharvest environment can alter volatile composition and flavor. As we better understand these relationships, postharvest environments could be optimized to maximize fruit flavor.

Controlled atmosphere (CA) storage and modified atmosphere packaging (MAP) may be used to prolong the storage and market life of small fruit. Controlled atmospheres are effective in reducing decay and maintaining quality. Atmosphere modification can be obtained through various types of CA chambers or through MAP. Berry crops benefit from high concentrations of carbon dioxide which are effective in inhibiting gray mold (Botrytis cinerea), the main cause of decay in small fruit (El-Goorani and Sommer, 1981). High humidity is also beneficial to maintain quality (Hardenburg et al., 1986). However, there is no strong evidence showing that low oxygen benefits storage life of small fruit and how these atmosphere modifications affect fruit volatiles is not well defined.

If injurious levels of $\mathrm{CO}_{2}$ or $\mathrm{O}_{2}$ develop (too low $\mathrm{O}_{2}$ or too high $\mathrm{CO}_{2}$ ), fermentation can be induced. This results in the accumulation of large quantities of ethanol, acetaldehyde, and ethyl acetate which can result in offflavors (Ke et al., 1994; Larsen and Watkins, 1995). Accumulation of ethyl acetate is believed to be responsible for fermented off-flavors that can develop in strawberries held in stressful atmospheres (Larsen, 1994). Low, non injurious concentrations of $\mathrm{O}_{2}$ may also inhibit the synthesis of some volatile compounds as seen in apples (Malus $\times$ domestica) (Lidster et al. 1983; Yahia 1994), however, additional research is needed to define these effects in small fruit.

Strawberry fruit held for $7 \mathrm{~d}$ in two types of MAP maintained good quality (Pérez et al., 1997b). Carbon dioxide concentrations increased to $5 \%$ and nearly $15 \%$ in the polyvinylchloride (PVC) and the polypropylene (PP) packages, respectively, while $\mathrm{O}_{2}$ concentrations were maintained above $15 \%$ in both packages. These atmospheres had no effect 


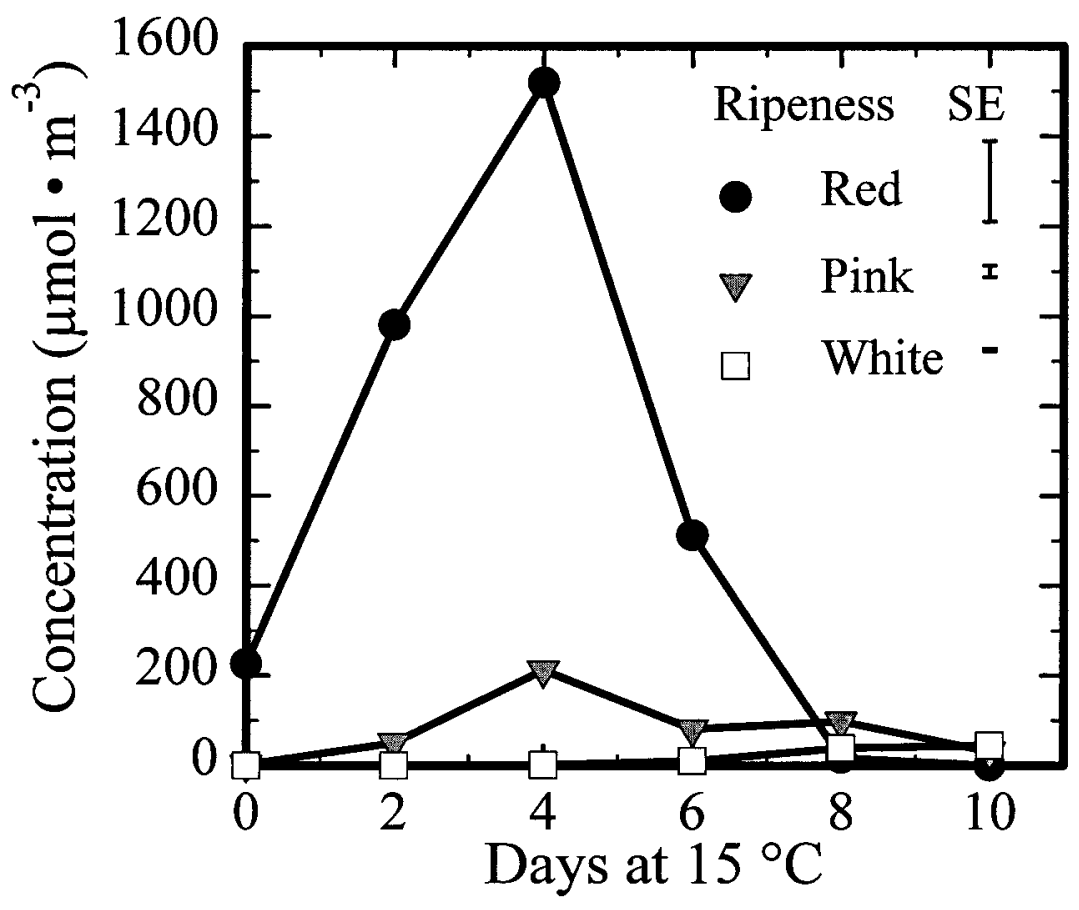

Fig. 3. Concentration of total volatiles in the head space over 'Kent' strawberry fruit during storage at $15^{\circ} \mathrm{C}\left(59^{\circ} \mathrm{F}\right)$. Fruit were harvested fully red, pink, or white; $1 \mu \mathrm{mol} \cdot \mathrm{m}^{-3}=23.8 \mathrm{ppm}$; adapted from Miszczak et al., 1995 . on the furanone content of the strawberry fruit. However, the high concentration of $\mathrm{CO}_{2}$ in the PP package began to stimulate ethanol production after $5 \mathrm{~d}$ when concentrations of $\mathrm{CO}_{2}$ had reached only $6 \%$. This enhanced ethanol production could lead to the development of off-flavors (Larsen, 1994) although it was not evaluated in this study.

Concentrations of $\mathrm{CO}_{2}>10 \%$ can inhibit the decay of fresh blueberries. However if $\mathrm{CO}_{2}$ levels become too high, the flavor of blueberries can be affected. When 'Bluecrop' fruit were stored for $12 \mathrm{~d}$ in MAP that developed concentrations of $\mathrm{CO}_{2}>20 \%$, fruit developed a storage off-flavor and a reduced blueberry flavor when compared with fruit from packages with $\mathrm{CO}_{2}$ concentrations $<20 \%$ (Rosenfeld et al., 1999). When 'Burlington' blueberries were held for 6 weeks in a CA atmosphere containing $0 \%, 15 \%$, or $25 \% \mathrm{CO}_{2}$, in combination with $15 \%$ $\mathrm{O}_{2}$, the $25 \% \mathrm{CO}_{2}$ atmosphere caused injury to the blueberries and stimulated the production of ethanol and ethyl acetate resulting in concentrations 18 - and 25 -fold greater than the $0 \%$ controls, respectively (Table 5 ). However, concentrations of the flavor volatiles butyrolactone and benzaldehyde were not affected. The non injurious atmospheres of $15 \% \mathrm{CO}_{2}$ had no effect on any of these four volatiles.

\section{Challenges for the future}

To maintain high quality of small fruit, a better understanding of the volatile chemicals responsible for flavor is needed. Better methodologies must be developed to identify and quantify all compounds contributing to the fruit aroma and flavor and research must continue to identify aroma active compounds in fresh berry crops. Our understanding of the chemistry responsible for flavor of small fruit is still limited and efforts need to continue combining sensory and chemical evaluation to develop a complete picture of the chemical basis of aroma and flavor. With the wide range of flavors present in different cultivars there are still opportunities to identify novel compounds that could give unique flavor characteristics and add value to small fruit.

With the diversity of chemistries contributing to the aroma volatiles of small fruit, we are challenged to understand the mechanisms of volatile biosynthesis and its regulation. Understanding the biochemistry of volatile synthesis may provide new opportunities to enhance small fruit flavor through genetic modification as well as by environmental control. Opportunities exist through both traditional breeding and molecular modifications to develop new cultivars with unique or enhanced flavors. In addition, by altering the timing of volatile synthesis through genetic or environment manipulation, flavor could be improved in fruit that are harvested under ripe to preserve firmness and postharvest handling characteristics.

Controlling changes in volatiles and flavor that occur during marketing and storage presents an additional challenge. Since the goal is to optimize fruit flavor upon delivery to the consumer, it is not enough to harvest fruit with good flavor; this flavor must be maintained or enhanced during storage and marketing. This produces many challenges to understanding the environmental and physiological factors affecting volatile composition during postharvest handling throughout the distribution chain. As technology develops to provide more precise control over the holding environment, including temperature, humidity, and atmosphere composition, these new capabilities can be used to optimize volatile composition and flavor. To reach this goal a multidisiplinary approach utilizing chemistry, sensory evaluation, genetic manipulation, physiology, and environmental control is required. Through efforts of this type, progress can be made to improve the value and quality of small fruit in the market place.
Table 5. Head space concentration of volatile compounds from 'Burlington' highbush blueberry fruit following 6 weeks storage at $0{ }^{\circ} \mathrm{C}\left(32{ }^{\circ} \mathrm{F}\right)$ in atmospheres containing $0 \%, 15 \%$, or $25 \%$ carbon dioxide $\left(\mathrm{CO}_{2}\right)$ and $15 \%$ oxygen (from Forney et al., unpublished data).

\begin{tabular}{lcccc}
\hline \multirow{2}{*}{$\begin{array}{l}\text { CO } \\
\text { (\%) }\end{array}$} & \multicolumn{4}{c}{ Normalized area counts } \\
\cline { 2 - 5 } & Ethanol & Ethyl acetate & Butyrolactone & Benzaldehyde \\
\hline 0 & 4.3 & 0.56 & 2.1 & 3 \\
15 & 5.3 & 0.52 & 3.1 & 2.9 \\
25 & 77.1 & 14.1 & 2.6 & 2.5
\end{tabular}

${ }^{{ }^{2}}$ eak area count from gas chromatography-mass spectroscopy analysis normalized against the peak area of a $4 \mathrm{ng}$ dodecane standard. 


\section{Literature cited}

Baloga, D.W., N. Vorsa, and L. Lawter. 1995. Dynamic headspace gas chromatography-mass spectrometry analysis of volatile flavor compounds from wild diploid blueberry species. Amer. Chem. Soc. Symp. Ser. 596:235-247.

Borejsza-Wysocki, W., S.K. Goers, R.N. McArdle, and G. Hrazdina. 1992. ( $p$ Hydroxyphenyl)butan-2-one levels in raspberries determined by chromatographic and organoleptic methods. J. Agr. Food Chem. 40:1176-1177.

Buttery, R.G. 1981. Vegetable and fruit flavors, p. 175-216. In: R. Teranishi, R.A. Flath, and H. Sugisawa (eds.). Flavor research recent advances. Marcel Dekker, New York.

de Ancos, B., E. Ibañez, G. Reglero, and M.P. Cano. 2000. Frozen storage effects on anthocyanins and volatile compounds of raspberry fruit. J. Agr. Food Chem. 48:873-879.

Devos, M., F. Patte, J. Rouault, P. Laffort, and L.J. Van Gemert. 1990. Standardized human olfactory thresholds. IRL Press, Oxford, U.K.

Di Cesare, F., R. Nani, M. Proietti, and R. Giombelli. 1999. Composizione volatile del fruitto e del succo di cultivar di mirtillo coltivate in Italia. Industrie Alimentari 38:277-282.

Dickinson, T.A., J. White, J.S. Kauer, and D.R. Walt. 1996. A chemical-detecting system based on a cross-reactive optical sensor array. Nature 382:697-700.

Dirinck, P.J., H.L. De Pooter, G.A. Willaert, and N.M. Schamp. 1981. Flavor quality of cultivated strawberries: The role of sulfur compounds. J. Agr. Food Chem. 29:316-321.

Douillard, C. and E. Guichard. 1990. The aroma of strawberry (Fragaria ananassa): Characterisation of some cultivars and influence of freezing. J. Sci. Food Agr. 50:517-531

El-Goorani, M.A. and N.F. Sommer. 1981. Effects of modified atmospheres on postharvest pathogens of fruit and vegetables. Hort. Rev. 3:412-461.

Flath, R.A. 1981. Identification in flavor research, p. 83-123. In: R. Teranishi, R.A. Flath, and H. Sugisawa (eds.). Flavor research recent advances. Marcel Dekker. New York.

Forney, C.F., W. Kalt, and M.A. Jordan. 2000. The composition of strawberry aroma is influenced by cultivar, maturity, and storage. HortScience 35:1022-1026.

Forney, C.F., W. Kalt, J.E. McDonald, and M.A. Jordan. 1998. Changes in strawberry fruit quality during ripening on and off the plant. Acta Hort. 464:506.

Gomes da Silva, M.D.R. and H.J. Chaves das Neves. 1997. Differentiation of strawberry varieties through purge-and-trap HRGC-MS, HRGC-FTIR and principal component analysis. J. High Resolution Chromatography 20:275-283.

Gomes da Silva, M.D.R. and H.J. Chaves das Neves. 1999. Complementary use of hyphenated purge-and-trap gas chromatography techniques and sensory analysis in the aroma profiling of strawberries (Fragaria ananassa). J. Agr. Food Chem. 47:4568-4573.

Guichard, E. 1982. Identification of the flavoured volatile components of the raspberry cultivar Lloyde George. Sci. Aliments 2:173-185.

Guichard, E. 1984. Formation of volatile components of two raspberry cultivars during the ripening. Sciences des Aliments 4:459-472.

Hardenburg, R.E., A.E. Watada, and C.Y. Wang. 1986. The commercial storage of fruits, vegetables, and florist and nursery stocks. USDA Agr. Hdbk. 66.

Hirvi, T. 1983. Mass fragmentographic and sensory analyses in the evaluation of the aroma of some strawberry varieties. Lebensmittel-Wissenshaft und Technologie 16:157-161.

Hirvi, T. and E. Honkanen. 1982. The volatiles of two new strawberry cultivars, 'Annelie' and 'Alaska Pioneer' obtained by backcrossing of cultivated strawberries with wild strawberries, Fragaria vesca, Rügen and Fragaria virginiana. Zeitschrift. fur Lebensmittel-Untersuchung und Forschung 175:113-116.

Hirvi, T. and E. Honkanen. 1983. The aroma of blueberries. J. Sci. Food Agr. 34:992-998.

Honkanen, E., T. Pyysalo, and T. Hirvi. 1980. The aroma of Finnish raspberries, Rubus idaeus L. Zeitschrift. fur Lebensmittel-Untersuchung und Forschung 171:180-182.

Horvat, R.J. and S.D. Senter. 1985. Comparison of the volatile constituents from rabbiteye blueberries (Vaccinium ashei) during ripening. J. Food Sci. 50:429-431, 436.

Horvat, R.J., W.S. Schlotzhauer, O.T. Chortyk, S.F. Nottingham, and J.A. Payne. 1996. Comparison of volatile compounds from rabbiteye blueberry (Vaccinium ashei) and deerberry (V.stamineum) during maturation. J. Essential Oil Res. 8:645-648.

Ibáñez, E., López-Sebastián, E. Ramos, J. Tabera, and G. Reglero. 1998. Analysis of volatile fruit components by headspace solid-phase microextraction. Food Chem. 63:281-286.

Ito, O., H. Sakakibara, I. Yajima, and K. Hayashi. 1990. The changes in the volatile components of strawberries with maturation, p. 69-72. In: Y. Bessière and A.F. Thomas (eds.). Flavour science and technology. John Wiley, New York.

Ke, D., L. Zhou, and A.A. Kader. 1994. Mode of oxygen and carbon dioxide action on strawberry ester biosynthesis. J. Amer. Soc. Hort. Sci. 119:971-975.

Kinoshita, O. and M. Nagata. 1998. Smell concentration and fruit quality-Measurement of smell concentration of strawberries using a semiconductor smell sensor. J. Jpn. Soc. Agr. Machinery 60:158-160.

Larsen, M. 1994. Volatile compounds formed in strawberries under anaerobic conditions and their influence on off-flavour formation. Trends Flavour Res. 35:421424.

Larsen, M. and L. Poll. 1990. Odour thresholds of some important aroma compounds in raspberries. Zeitschrift. fur LebensmittelUntersuchung und -Forschung 191:129131

Larsen, M. and L. Poll. 1992. Odour thresholds of some important aroma compounds in strawberries. Zeitschrift. fur Lebensmittel-Untersuchung und Forschung 195:120-123.

Larsen, M., L. Poll, and C.E. Olsen. 1992. Evaluation of the aroma composition of some strawberry (Fragaria ananassa Duch.) cultivars by use of odour threshold values. Zeitschrift. fur LebensmittelUntersuchung und -Forschung 195:536539.

Larsen, M. and C.B. Watkins. 1995. Firmness and concentrations of acetaldehyde, ethyl acetate and ethanol in strawberries stored in controlled and modified atmospheres. Postharvest Biol. Technol. 5:3950.

Latrasse, A. 1991. Fruits III, p. 329-387. In: H. Maarse (ed.). Volatile compounds in foods and beverages. Marcel Dekker, New York.

Lidster, P.D., H.J. Lightfoot, and K.B. McRae. 1983. Production and regeneration of principal volatiles in apples stored in modified atmospheres and air. J. Food. Sci. 48: 400-402.

Lugemwa, F.N., W. Lwanda, M.D. Bentley, M.J. Mendel, and A.R. Alford. 1989. Volatiles of wild blueberry, Vaccinium angustifolium: Possible attractants for the blueberry maggot fruit fly. J. Agr. Food Chem. 37:232-233.

Miszczak, A., C.F. Forney, and R.K. Prange. 1995. Development of aroma vola- 
tiles and color during postharvest ripening of 'Kent' strawberries. J. Amer. Soc. Hort. Sci. 120:650-655.

Newman, A. 1991. Electronic noses. Anal. Chem. 63:585-588.

Parliment, T.H. and M.G. Kolor. 1975. Identification of the major volatile components of blueberry. J. Food Sci. 40:762763.

Parliment, T.H. and R. Scarpellino. 1977. Organoleptic techniques in chromatographic food flavor analysis. J. Agr. Food Chem. 25:97-99.

Pérez, A.G., J.J. Rios, C. Sanz, and J.M. Olías. 1992. Aroma components and free amino acids in strawberry variety Chandler during ripening. J. Agr. Food Chem. 40:2232-2235.

Pérez, A.G., R. Olías, C. Sanz, and J.M. Olías. 1996. Furanones in strawberries: Evolution during ripening and postharvest shelf life. J. Agr. Food Chem. 44:36203624 .

Pérez, A.G., C. Sanz, R. Olías, J.J. Ríos, and J.M. Olías. 1997a. Aroma quality evaluation of strawberry cultivars in southern Spain. Acta Hort. 439:337-340.

Pérez, A.G., C. Sanz, R. Olías, J.J. Ríos, and J.M. Olías. 1997b. Effect of modified atmosphere packaging on strawberry quality during shelf-life, p. 153-158. In: A.A. Kader (ed.). CA'97 Proceedings. vol 3: Fruits Other than Apples and Pears. Postharvest Hort. Ser. 19, Univ. Calif, Davis.

Pickenhagen, W., A. Velluz, J.P. Passerat, and G. Ohloff. 1981. Estimation of 2,5dimethyl-4-hydroxy-3(2H)-furanone (FURANEOL ${ }^{\circledR}$ ) in cultivated and wild strawberries, pineapples, and mangoes. J. Sci. Food Agr. 32:1132-1134.

Polesello, S., F. Lovati, A. Rizzolo, and C. Rovida. 1993. Supercritical fluid extraction as a preparative tool for strawberry aroma analysis. J. High Resolution Chromatography 16:555-559.

Rizzolo, A. 1998. Use of gas-chromatography-olfactometry (GCO) to evaluate flavour characteristics in fruit products.
Atti-dell'Istituto-Sperimentale-per-laValorizzazione-Techoligica-dei-PtrodottiAgricoli, Milanol 9:5-24.

Roberts, D.D. and T.E. Acree. 1996. Effects of heating and cream addition of fresh raspberry aroma using a retronasal aroma simulator and gas chromatography olfactometry. J. Agr. Food Chem. 44:39193925 .

Robertson, G.W., D.W. Griffiths, J.A.T Woodford, and A.N.E. Birch. 1995. Changes in the chemical composition of volatiles released by the flowers and fruits of the red raspberry ( $R$ ubusidaeus) cultivar Glen Prosen. Phytochemistry 38:11751179.

Rosenfeld, H.J., K.R. Meberg, K. Haffner, and H.A. Sundell. 1999. MAP of highbush blueberries: sensory quality in relation to storage temperature, film type and initial high oxygen atmosphere. Postharvest Biol. Technol. 16:27-36.

Sanz, C., D.G. Richardson, and A.G. Pérez. 1995. 2,5-Dimethyl-4-hydroxy-3(2H)furanone and derivatives in strawberries during ripening, p. 268-275. In: R.L. Rouseff and M.M. Leahy (eds.). Fruit flavors: Biogenesis, characterization, and authentication. Amer. Chem. Soc. Symp. Ser. 596.

Shamaila, M., B. Skura, H. Daubeny, and A. Anderson. 1993. Sensory, chemical and gas chromatographic evaluation of five raspberry cultivars. Food Res. Intl. 26:443449

Schreier, P. 1980. Quantitative composition of volatile constituents in cultivated strawberries, Fragaria ananassa cv. Senga Sengana, Senga Litessa and Senga Gourmella. J. Sci. Food Agr. 31:487-494.

Schultz, T.H., R. A. Flath, D.R. Black, D.G. Guadagni, W.G. Schultz, and R. Teranishi. 1967. Volatiles from Delicious apple essence-Extraction methods. J. Food Sci. 32:279-283.

Shu, C.K. B.D. Mookherjee, and C.T. Ho. 1985. Volatile components of the thermal degradation of 2,5-dimethyl-4-hydroxy$3(2 \mathrm{H})$-furanone. J. Agr. Food Chem. 33:446-448.
Simon, J.E., A. Hetzroni, B. Bordelon, G.E. Milnes, and D.J. Charles. 1996. Electronic sensing of aromatic volatiles for quality sorting of blueberries. J. Food Sci. 61:967-969, 972 .

Steffen, A. and J. Pawliszyn. 1996. Analysis of flavor volatiles using headspace solidphase microextraction. J. Agr. Food Chem. 44:2187-2193.

Song, J., L. Fan, and R.M. Beaudry. 1998. Application of solid phase microextraction and gas chromatography/time-of-flight mass spectrometry for rapid analysis of flavor volatiles in tomato and strawberry fruits. J. Agr. Food Chem. 46:3721-3726.

Sugisawa, H. 1981. Sample preparation: Isolation and concentration, p. 11-51. In: R. Teranishi, R.A. Flath, and H. Sugisawa (eds.). Flavor research recent advances. Marcel Dekker. New York.

Teranishi, R. 1981. Separations, p. 53-82. In: R. Teranishi, R.A. Flath, and H. Sugisawa (eds.). Flavor research recent advances. Marcel Dekker, New York.

Ueda, Y. and J.H. Bai. 1993. Effect of short term exposure of elevated $\mathrm{CO}_{2}$ on flesh firmness and ester production of strawberry. J. Jpn. Soc. Hort. Sci. 62:457-464.

Ulrich, D., E. Hoberg, A. Rapp, and S. Kecke. 1997. Analysis of strawberry flavour-Discrimination of aroma types by quantification of volatile compounds. Zeitschrift. fur LebensmittelUntersuchung und -Forschung 205:218223.

Vereshchagin, P.V. and A.A. Bezzubov. 1981. The composition of raspberry essential oils. Appl. Biochem. Microbiology 17:53-57.

Wampler, T.P. 1997. Analysis of food volatiles using headspace-gas chromatographic techniques, p. 27-58. In: Marsili, R. (ed.). Techniques for analyzing food aroma. Marcel Dekker, New York.

Weurman, C. 1969. Isolation and concentration of volatiles in food odor research. J. Agr. Food Chem. 17:370-384.

Yahia, E.M. 1994. Apple flavor. Hort. Rev. 16:197-234. 